\title{
Effect of Implementing Standardized Nursing Care on Chest Expansion and Pulmonary Function for Patients With Pleural Effusion
}

\author{
Amal Abdelnasser Mohamed ${ }^{1}$, Zein Elabedeen Zareh Hassan ${ }^{2}$, Mervat Anwar Abd EL-Aziz ${ }^{3}$ Asmaa Aly \\ Mahgoub ${ }^{4}$. \\ 1 Nursing specialist, Women Health Hospital, Assiut University, Assiut, Egypt. \\ 2 Professor, Anesthesia and intensive care Department, Faculty of medicine, Assiut University, Assiut, Egypt. \\ 3 Assistant professor, Critical care and emergency nursing Department, Faculty of Nursing, Assiut University, \\ Assiut, Egypt. \\ 4 Assistant professor, Critical care and emergency nursing Department, Faculty of Nursing, Assiut University, \\ Assiut, Egypt.
}

\begin{abstract}
Pleural effusion is a common disease and represents the disturbance of the normal mechanism of fluid formation and drainage from the pleural space. Aim of the study: was to evaluate the effect of implementing standardized nursing care on chest expansion and pulmonary function for patients with pleural effusion. Patients and Methods: randomized prospective research design was used to conduct this study; the study was carried out at Assiut University Hospitals. The study sample consisted of study group (30 patients) who received standardized nursing care by using chest physiotherapy and control group (30 patients) who received only routine hospital care. Chest expansion and pulmonary function were assessed before and after exercises in both groups, the study was conducted in one year. Tools: three tools were used. Results: show that there was a statistical significant difference between study and control groups in relation to chest expansion and pulmonary function ( $\mathrm{P}$-value < 0.05). Conclusion: Implementing standardized nursing care was significantly effective in improving chest expansion and pulmonary function in patients with pleural effusion. Recommendations: Implementing standardized nursing care in patients with pleural effusion is important for improving chest expansion and pulmonary function.
\end{abstract}

\section{Keywords: Effect, Pleual Effusion \& Standardized Nursing Care.}

\section{Introduction}

Pleural effusions are very common disease, and physicians of all specialties encounter them. A pleural effusion represents the disruption of the normal mechanisms of fluid formation and drainage from the pleural space (José \& Raed, 2014).

Pleural effusion is defined as a fluid collecton between the pleural leaves due to local/systemic disease of the pleura, lung or extrapulmonary organs. Normally, 0.1 to $0.2 \mathrm{ml} / \mathrm{kg}$ of fluid is present in the pleural leaves to facilitate pleural movement. When the balance between the producton and reabsorpton of this fluid deteriorates, it becomes pleural effusion (Incekara et al., 2018).

The symptoms depend on the fluid amount and the underlying cause. Many patients have no symptoms when a pleural effusion is discovered. Possible symptoms include dyspnea, pleuritic chest pain and dry nonproductive cough. Physical findings are dullness on percussion, reduced tactile fremitus, and diminished or absent breath sounds (José et al., 2014).

The role of the nurse in pleural effusion management is multifaceted, and comprises careful monitoring of the patient's vital signs, central venous pressure (CVP), level of consciousness and fluid input /urine output, measuring chest, pulmonary function and use chest physiotherapy which can enhance and improve chest epansion and pulmonary function of these patients (Murphy, 2010).

This study was designed to determine the effect of standardized nursing care by using chest physiotherapy programme on chest expansion and pulmonary function for patients with pleural effusion.

\section{Significance of the study}

Pleural effusion is common to be detected in critically ill patients as the rate of admission of patients with pleural effusion in intensive care units in the previous year (2018) in Assiut university hospital (including General ICU, Trauma ICU and Chest ICU ) is about 144 patients. Those patients with pleural effusions are of little clinical nursing care as it can be neglected until patient condition be worsen; although if it detected early can be managed easily through using chest physiotherapy, breathing exercises and follow the standard nursing care which can improve the patient condition. 
The aim of the study

General objective

To determine the effect of implementing standardized nursing care by using chest physiotherapy on patient outcomes in critically ill patients with pleural effusion.

Specific objective

1. To determine the efficacy of chest mobility exercises, stacked breathing, segmental breathing, deep breathing exercise and using incentive spirometer on chest expansion in critically ill patients with pleural effusion.

2. To determine the efficacy of chest mobility exercises, stacked breathing, segmental breathing, deep breathing exercise and using incentive spirometer on pulmonary function in critically ill patients with pleural effusion.

Research hypothesis

Chest expansion and pulmonary function in critically ill patients with pleural effusion will be significantly improve after implementing standardized nursing care by using chest physiotherapy or will not be improved.

\section{2- Subjects and Methods}

Research design: True experimental ( randomized prospective ) research design was used to conduct this study.

\section{Study variables}

- Independent variable in this study was the impact of standardized nursing care by using chest physiotherapy .

- Dependent variables were the patients' outcomes which included:-

1. Chest expansion.

2. Pulmonary functions.

3. Duration of ICU stay.

\section{Setting of the study}

This study was carried out in 3 settings included chest intensive care unit, general and trauma intensive care unit at Assiut university hospital.

\section{Sampling}

- Sample size calculations: A power calculation estimated that in order to detect an effect size of 0.29 difference in mean of pulmonary function between the two studied groups, with a p-value $<0.05$ and $80 \%$ power, confidence level 0.95 , a sample size of 20 patients for each group was needed. However, 60 patients were attempted in this research work to avoid non-response rate (30 for each group). This calculated using G Power 3.1 (Hsieh et al., 1998).

- A convenience sample of 60 male and female adult patients was taken; the patients were classified into two equal groups, 30 patients for each group. Study group (30 patients) who received the standardized nursing care and control group (30 patients) who received the routine hospital care only. The study was conducted in one year from 1 / 7 / 2019 to 1 / $7 / 2020$.

Inclusion criteria

1- Age of 20-60 years.

2- patients of both genders.

3- patients diagnosed as pleural effusion.

4- patients with asymmetrical chest expansion.

Exclusion criteria:

1- Orthopedic conditions.

2- Pleural effusion due to transudate conditions like: liver cirrhosis, .... etc.

3- Malignant conditions.

4- Cognitive impairments.

Study tools

Three tools used in this study were developed by the researcher and included:-

Tool one: Pleural effusion assessment sheet

This tool was developed by the researcher after reviewing of literatures [(Knaus et al., 1985), (Kakizaki et al., 1999), (Olsén et al., 2011), \& (Kollef, 2012)] and used to monitor hemodynamic parameters, assessment of respiratory system, assessment of laboratory findings, fluid balance in addition to socio-demographic and medical data. It includes 5 parts:-

Part I: Personal characteristics and medical data: Personal characteristics data included patient's code number, age and sex. Medical data included past history, present illness, cause of admission, date of admission, date of discharge and length of ICU stay.

Part II: APACHE II Scoring System \& assessment of hemodynamic status

APACHE II Scoring System which originated from (Knaus et al., 1985) and adopted from (Saber et al., 2018) and it was done in the first $24 \mathrm{hr}$ of admission. To assess hemodynamic parameters system included (Mean arterial pressure (MAP) taken from bed side monitor, heart rate (HR), temperature, respiratory rate and CVP readings) Davenport \& Stevens, (2008) and laboratory findings every day.

Part III: Assessment of respiratory system and consisted of

(1) Assessment of chest expansion originated from ( Kakizaki et al.,1999) and adopted from (Olsén et al., 2011) by using measuring tape (marked in $\mathrm{mm}$ ). Basal expansions were determined by using a tape measure. Each measurement was obtained after maximal expiration followed by maximum inspiration and another maximal expiration. Measurements were taken three times and the mean of the three values was recorded. 
(2) Assessment of pulmonary functions adopted from (Kollef, 2012) and included:-

(a) Sabrasez breath holding test:- patient was asked to take a full but not too deep breath and hold it as long as possible and cardiopulmonary reserve and volume capacity were evaluated.

- > 25 SEC : Normal Cardiopulmonary Reserve (CPR)

- 15-25 SEC : Limited Cardiopulmonary Reserve (CPR)

- $<15$ SEC : Very poor Cardiopulmonary Reserve (CPR)

- 25-30 SEC : $3500 \mathrm{ml}$ volume capacity (VC)

- 20-25 SEC : $3000 \mathrm{ml}$ volume capacity (VC)

- 15-20 SEC : $2500 \mathrm{ml}$ volume capacity (VC)

- 10-15 SEC : $2000 \mathrm{ml}$ volume capacity (VC)

- 5 - 10 SEC : $1500 \mathrm{ml}$ volume capacity (VC)

(b) Schneider's match blowing test: the patient was asked to blow a match stick from a distance of 6" $(15 \mathrm{cms})$ With mouth wide open, chin rested/supported, no purse lipping, no head movement, no air movement in the room, mouth and match at the same level and maximum breathing capacity and forced expiratory volume were evaluated.

$\checkmark$ Cannot blow out a match

- maximum breathing capacity ( MBC) $<60$ L/min.

- forced expiratory volume in one second ( FEV1) $<1.6 \mathrm{~L}$.

$\checkmark$ Able to blow out a match:-

- maximum breathing capacity (MBC) > 60 $\mathrm{L} / \mathrm{min}$

- forced expiratory volume in one second (FEV1) > 1.6L.

$\checkmark$ MODIFIED MATCH TEST:-

DISTANCE maximum breathing capacity (MBC) 9"

6"

3"

$>150 \mathrm{~L} / \mathrm{MIN}$.

$>60 \mathrm{~L} / \mathrm{MIN}$.

$>40 \mathrm{~L} / \mathrm{MIN}$.

Tool two: Chest physiotherapy sheet

This tool was developed by the researcher and used to assess exercises done to the patient and includes 5 parts

Part (1): Chest mobility exercise originated from (Milojević et al., 2003 \& AARC (AARC Clinical Practice Guideline, 1991) and adopted from ( ikram et al., 2012). It included any exercises that combine active movements of the trunk or extremities with deep breathing. Limb exercises (i.e., passive, active assisted, or active) will be performed in bed or in a seated position, depending on medical advice, with the aim of maintaining joint range of motion, improving soft-tissue length, muscle strength and function, and decreasing the risk of thromboembolism.

Part (2) : Stacked breathing originated from (Providence Care, 2008) and adopted from (Agostini, 2009) which works by allowing air to move more deeply into the lungs and opens up alveoli that may have closed, while exercising the lung tissue and chest wall, keeping them flexible.

Part (3) : Segmental breathing originated from (Milojević et al., 2003) and adopted from (Gunjal et al., 2015) which is questionable whether a patient can be taught to expand localized areas of the lung while keeping other areas quiet. It is known, however, that hypoventilation does occur in certain areas of these lungs because of pain and muscle guarding after surgery.

Part (4): Deep breathing exercise originated from (Milojević et al., 2003) and adopted from (Gunjal et al., 2015).

Part (5): Incentive spirometer originated from (Milojević et al., 2003) and adopted from (Gunjal et al., 2015). Using the incentive spirometer, also called a breathing exerciser, helps to take deep breaths to open the air sacs in the lungs.

Tool three: Patients' outcomes evaluation sheet which was developed by the researcher and used to assess the effect of standardized nursing care on chest expansion, pulmonary functions and duration of ICU stay as patients were evaluated 3 times; in the first day of the study, after three day of the study and in the last day of the study.

\section{Methods}

The study was conducted throughout three main phases, which were preparatory phase, implementation phase and evaluation phase:

Preparatory phase

1- Seeking official and non official permission to conduct the study were obtained by the researcher from the head of all intensive care units after explanation of aim and nature of the study.

2- Construction for data collection tools after extensive literature of review.

3- Content validity: The tools were tested for content related validity by jury of 5 specialists in the field of critical care nursing and critical care medicine from Assiut University then the tools were designed in their final format and tested for reliability using internal consistency for all of the tools which was measured using cronbach's test. The tools proved to be reliable (0.823).

4- A pilot study: was conducted on 6 patients to test the feasibility and applicability of the tools and the analysis of the pilot study revealed that minimal modifications are required, these 
necessary modifications were done and the pilot study subjects were excluded from the actual study.

\section{5- Ethical consideration}

- Research proposal was approved from Ethical Committee in the faculty of nursing.

- There was no risk for study subject during application of the study.

- The study followed common ethical principles in clinical research.

- Written consent was obtained from patients or guidance that participated in the study, after explaining the nature and purpose of the study.

- Patient was assured that the data of this research was not be reused without second permission.

- Confidentiality and anonymity was assured.

- Patients had the right to refuse to participate or withdraw from the study without any rational at any time.

Data collection: Data were collected in one year from 1/7/2019 to 1/ 7/2020 and the data were collected from the first day of admission after stabilization of the patient's condition and until the patient improved or discharged from the ICU, every day and every shift .

\section{Implementation phase}

- Firstly socio-demographic data and medical data was obtained by the researcher by using tool (1) for both groups.

- Assessment of the study and control groups was done by using tool (1).

- After getting ethical clearance patients were enrolled in the study, patients were selected based on the inclusion and exclusion criteria. Following an initial assessment, the patients were assigned to one of the two groups by block randomization.

- After randomizing the patient to one of two groups, before the intervention ; chest expansion was measured by using measuring tape (marked in $\mathrm{mm}$ ) according to Kakizaki et al., (1999). Patients were prepared for measurement unclothed from the waist up, with the arms bent, hands on heads, standing upright, and facing the front.

- The patient was instructed as "Breathe in maximally and make yourself as big as possible" and "Breathe out maximally and make yourself as small as possible"

- Circumferential measurements were performed with a tape measure, and anteroposterior and transverse measurements using caliper. Measurements are performed three times by the same researcher and mean values will be recorded. At circumferential measurement by tape measure; the difference between deep inspiration and deep expiration will be determined by measuring chest circumferences at the level of the fourth intercostal space. For anteroposterior measurement, the front tip of the caliper was placed on the xiphisternal junction. For transverse measurement, the calipers will be placed on either side of the virtual line passing through the same junction.

- Before the intervention bed side pulmonary function tests were done and repeated after 1 hour of the exercise.

- Study group was received Chest mobility exercises with Incentive spirometer according to guidelines given by Kisner (Milojević, 2003) and segmental breathing according to guidelines given by Kisner (Milojević et al., 2003) and breath stacking technique explained by Providence Care .

- The patient in the study group was instructed to perform the intervention 3 times per day, 7 8 times per session for one week.

\section{Evaluation phase}

This phase was done to evaluate effect of applying standardized nursing care on patients' outcomes (chest expansion and pulmonary function) and each patient was evaluated 3 times from admission till discharge (in the first day of the study, after 3 days of the study and in the last day of the study).

\section{Statistical analysis}

Data were computerized and analyzed by computer programmed SPSS (ver.16). Data were presented by using descriptive statistics in the form of frequencies and percentages or means \pm standard deviations for qualitative data. Quantitative data were compared using Independent samples t- test for comparisons among two groups. Qualitative variables were compared using chi-square test to determine significance. The critical value of the tests "P" was considered statistically significant when $\mathrm{P}$ less than 0.05 . 


\section{Results}

Table (1): Distribution of personal characteristics of study and control groups, (total patients' number = 60 ):-

\begin{tabular}{|c|c|c|c|c|}
\hline \multirow{2}{*}{\multicolumn{2}{|c|}{ Personal characteristics }} & \multicolumn{2}{|c|}{ Study $(n=30) \quad$ Control $(n=30)$} & \multirow{2}{*}{ P-value } \\
\hline & & no. & $\%$ & \\
\hline \multicolumn{4}{|l|}{ Sex: } & \multirow{3}{*}{0.793} \\
\hline Male & 40.0 & 43.3 & & \\
\hline Female & 60.0 & 56.7 & & \\
\hline \multicolumn{4}{|l|}{ Age: (years) } & \multirow{3}{*}{0.750} \\
\hline Mean \pm SD & $41.87 \pm 11.05$ & \multicolumn{2}{|l|}{$42.80 \pm 11.54$} & \\
\hline Range & $22.0-60.0$ & \multicolumn{2}{|l|}{$23.0-56.0$} & \\
\hline
\end{tabular}

Table (2): Distribution of clinical data of study and control groups, (total patients' number $=60$ ):-

\begin{tabular}{|c|c|c|c|c|c|}
\hline \multirow{2}{*}{ Clinical data } & \multicolumn{2}{|c|}{ Study $(n=30)$} & \multicolumn{2}{|c|}{$\operatorname{Control}(n=30)$} & \multirow{2}{*}{ P-value } \\
\hline & no. & $\%$ & no. & $\%$ & \\
\hline \multicolumn{6}{|l|}{ Present illness: } \\
\hline AKI & 9 & 30.0 & 8 & 26.7 & 0.774 \\
\hline Pneumonia & 13 & 43.3 & 9 & 30.0 & 0.284 \\
\hline Pulmonary embolism & 7 & 23.3 & 6 & 20.0 & 0.754 \\
\hline HTN & 5 & 16.7 & 6 & 20.0 & 0.739 \\
\hline \multirow{2}{*}{$\begin{array}{l}\text { Intestinal injury } \\
\text { Others }\end{array}$} & 1 & 3.3 & 1 & 3.3 & 1.000 \\
\hline & 2 & 6.7 & 5 & 16.7 & 0.424 \\
\hline ICU stay (days) Mean \pm SD & \multicolumn{2}{|c|}{$10.27 \pm 18.35$} & \multicolumn{2}{|c|}{$7.57 \pm 3.72$} & 0.433 \\
\hline
\end{tabular}

Ns: There is no significant difference P-value $>0.05$

*significant difference at $P$-value $<0.05$

- Independent samples t-test -AKI: Acute kidney injury

-HTN: Hypertension

Table (3): Distribution of study and control groups in relation to hemodynamic monitoring in the first day of the study, after three days and in the last day (total patients' number $=60$ )

\begin{tabular}{|c|c|c|c|c|c|c|c|c|c|}
\hline \multirow{3}{*}{$\begin{array}{c}\text { Hemodynam } \\
\text { ic } \\
\text { Monitoring }\end{array}$} & \multirow{2}{*}{\multicolumn{3}{|c|}{$\begin{array}{c}\text { Study }(n=30) \\
\text { Mean }+ \text { SD }\end{array}$}} & & $\begin{array}{c}\text { Control }(n= \\
\text { 30) }\end{array}$ & & \multirow{2}{*}{\multicolumn{3}{|c|}{ P-value }} \\
\hline & & & & & Mean \pm SD & & & & \\
\hline & $1^{\text {st }}$ day & After 3 days & In the last day & $1^{\text {st }}$ day & $\begin{array}{c}\text { After } 3 \text { days } \\
\text { day }\end{array}$ & In the last & $1^{\text {st }}$ day & $\begin{array}{c}\text { After } 3 \\
\text { days }\end{array}$ & $\begin{array}{c}\text { In the } \\
\text { last day }\end{array}$ \\
\hline Temperature & $37.61 \pm 0.57$ & $37.31 \pm 0.35$ & $37.24 \pm 0.31$ & $37.65 \pm 0.65$ & $37.32 \pm 0.52$ & $37.37 \pm 0.48$ & 0.800 & 0.883 & 0.207 \\
\hline Heart rate & $\begin{array}{c}109.93 \pm \\
23.26\end{array}$ & $97.10 \pm 16.65$ & $94.97 \pm 18.98$ & $106.57 \pm 23.41$ & $103.87 \pm 20.91$ & $106.23 \pm 18.87$ & 0.579 & 0.171 & $0.025 *$ \\
\hline MAP & $94.57 \pm 15.74$ & $90.17 \pm 13.34$ & $85.07 \pm 12.76$ & $\begin{array}{c}84.43 \pm \\
13.62\end{array}$ & $\begin{array}{c}83.90 \pm \\
11.75\end{array}$ & $82.67 \pm 11.65$ & $0.010 *$ & 0.058 & 0.450 \\
\hline R.R & $25.33 \pm 6.74$ & $18.83 \pm 4.19$ & $15.63 \pm 3.22$ & $24.37 \pm 6.18$ & $23.47 \pm 8.05$ & $22.63 \pm 8.16$ & 0.565 & $0.007 *$ & $0.000^{*}$ \\
\hline CVP & $17.07 \pm 5.90$ & $14.40 \pm 3.72$ & $13.23 \pm 3.76$ & $14.63 \pm 7.55$ & $15.47 \pm 5.02$ & $16.07 \pm 6.10$ & 0.170 & 0.353 & $0.034 *$ \\
\hline GCS & $14.83 \pm 0.46$ & $15.00 \pm 0.00$ & $15.00 \pm 0.00$ & $14.83 \pm 0.65$ & $15.00 \pm 0.00$ & $15.00 \pm 0.00$ & 1.000 & -- & -- \\
\hline WBC & $17.67 \pm 7.50$ & $12.75 \pm 5.11$ & $10.00 \pm 3.70$ & $13.41 \pm 6.60$ & $15.05 \pm 7.52$ & $14.61 \pm 6.86$ & $0.023 *$ & 0.171 & $0.002 *$ \\
\hline Serum Na & $137.98 \pm 5.23$ & $137.19 \pm 3.43$ & $136.65 \pm 3.90$ & $136.28 \pm 4.95$ & $138.94 \pm 4.70$ & $139.36 \pm 3.95$ & 0.201 & 0.105 & $0.010^{*}$ \\
\hline Serum K & $3.89 \pm .51$ & $3.74 \pm 0.57$ & $3.94 \pm 0.54$ & $4.04 \pm 0.81$ & $4.09 \pm 0.72$ & $3.89 \pm 0.57$ & 0.411 & $0.040 *$ & 0.743 \\
\hline S. creatinine & $137.04 \pm 141.87$ & $133.11 \pm 119.25$ & $107.77 \pm 92.26$ & $151.32 \pm 112.1$ & $168.31 \pm 148.50$ & $185.04 \pm 196.08$ & 0.667 & 0.316 & 0.056 \\
\hline Hematocrit & $31.90 \pm 7.98$ & $33.18 \pm 7.50$ & $34.08 \pm 5.79$ & $35.20 \pm 8.95$ & $36.33 \pm 8.31$ & $36.31 \pm 7.63$ & 0.137 & 0.128 & 0.207 \\
\hline $\mathrm{FIO}_{2}$ & $43.30 \pm 9.80$ & $32.11 \pm 8.76$ & $37.00 \pm 18.38$ & $46.95 \pm 11.05$ & $41.81 \pm 11.05$ & $44.35 \pm 13.36$ & 0.252 & $0.005^{*}$ & 0.483 \\
\hline Arterial PH & $7.41 \pm 0.09$ & $7.43 \pm 0.08$ & $7.40 \pm 0.06$ & $7.39 \pm 0.07$ & $7.39 \pm 0.09$ & $7.40 \pm 0.07$ & 0.236 & 0.092 & 0.789 \\
\hline${\text { Serum } \mathrm{HCO}_{3}}_{3}$ & $19.91 \pm 5.58$ & $21.99 \pm 3.76$ & $23.00 \pm 3.72$ & $20.72 \pm 7.22$ & $22.06 \pm 8.06$ & $22.56 \pm 6.84$ & 0.629 & 0.969 & 0.756 \\
\hline $\mathrm{PO}_{2}$ & $100.04 \pm 35.57$ & $104.07 \pm 30.33$ & $82.22 \pm 18.09$ & $103.19 \pm 38.20$ & $89.53 \pm 28.56$ & $83.21 \pm 23.22$ & 0.742 & 0.061 & 0.854 \\
\hline $\mathrm{PCO}_{2}$ & $32.04 \pm 9.21$ & $30.65 \pm 6.60$ & $33.21 \pm 4.38$ & $33.50 \pm 14.52$ & $32.33 \pm 14.75$ & $31.88 \pm 11.34$ & 0.644 & 0.571 & 0.552 \\
\hline
\end{tabular}

Ns: There is no significant difference P-value $>0.05 \quad$ *significant difference at P-value $<0.05$ -MAP: mean arterial pressure

-GCS : Glasgow coma scale was not applicable for sedated patients.

-PH: acid base balance
-R.R: respiratory rate.

$-\mathbf{P a c o}_{2}$ : partial pressure of carbon dioxide
-Chi-square test

- CVP : central venous pressure

-WBC: white blood cells

-Pao 2 : partial pressure of oxygen 
Table (4): Comparison between the studied groups in relation to chest expansion in all period of the study, (total patients' number $=30$ ).

\begin{tabular}{|c|c|c|c|}
\hline \multirow{2}{*}{ Chest expansion } & Study $(n=30)$ & Control $(n=30)$ & \multirow{2}{*}{ P-value } \\
\hline & Mean \pm SD & Mean \pm SD & \\
\hline \multicolumn{4}{|c|}{ The first day of the study :- } \\
\hline Before & $0.88 \pm 0.40$ & $0.93 \pm 0.39$ & 0.662 \\
\hline After & $1.30 \pm 0.43$ & $1.01 \pm 0.42$ & $0.009 *$ \\
\hline \multicolumn{4}{|c|}{ After three day of the study:- } \\
\hline Before & $1.49 \pm 0.42$ & $1.22 \pm 0.39$ & $0.014^{*}$ \\
\hline After & $1.89 \pm 0.32$ & $1.24 \pm 0.37$ & $0.000 *$ \\
\hline \multicolumn{4}{|c|}{ In the last day of the study:- } \\
\hline Before & $2.00 \pm 0.32$ & $1.45 \pm 0.40$ & $0.000^{*}$ \\
\hline After & $2.35 \pm 0.26$ & $1.56 \pm 0.38$ & $0.000^{*}$ \\
\hline
\end{tabular}

Ns: There is no significant difference P-value $>0.05 \quad$ *significant difference at $P$-value $<0.05$

- Independent samples t-test.

Table (5): Distribution of study and control groups in relation to bedside pulmonary function tests in the first day of the study, (total patients' number $=60$ ).

\begin{tabular}{|c|c|c|c|c|c|}
\hline \multirow{2}{*}{ Bedside pulmonary function tests } & \multicolumn{2}{|c|}{ Study $(n=30)$} & \multicolumn{2}{|c|}{ Control $(n=30)$} & \multirow{2}{*}{ P-value } \\
\hline & no. & $\%$ & no. & $\%$ & \\
\hline \multicolumn{6}{|l|}{ Before exercise: } \\
\hline \multicolumn{5}{|l|}{ Cardiopulmonary Reserve (CPR): } & \multirow{3}{*}{1.000} \\
\hline Limited CPR & 17 & 56.7 & 17 & 56.7 & \\
\hline Very poor CPR & 13 & 43.3 & 13 & 43.3 & \\
\hline Volume capacity (VC) & $2066.67 \pm 430.18$ & $1916.67 \pm 32$ & 23.86 & 0.132 & \\
\hline \multicolumn{5}{|l|}{$\mathrm{MBC} \geq 60 \mathrm{~L} / \mathrm{min} \& \mathrm{FEV} 1 \geq 1.6 \mathrm{~L}:$} & \multirow{3}{*}{0.602} \\
\hline Yes & 14 & 46.7 & 12 & 40.0 & \\
\hline No & 16 & 53.3 & 18 & 60.0 & \\
\hline \multicolumn{6}{|l|}{ After exercise: } \\
\hline \multicolumn{5}{|l|}{ Cardiopulmonary Reserve (CPR): } & \multirow{4}{*}{$0.008^{*}$} \\
\hline Limited CPR & 19 & 63.3 & 17 & 56.7 & \\
\hline Very poor CPR & 5 & 16.7 & 13 & 43.3 & \\
\hline Normal & 6 & 20.0 & 0 & 0.0 & \\
\hline Volume capacity (VC) & $2366.67 \pm 413.84$ & $1983.33 \pm 35$ & 9.20 & $0.000 *$ & \\
\hline \multicolumn{5}{|l|}{$\mathrm{MBC} \geq 60 \mathrm{~L} / \mathrm{min} \& \mathrm{FEV} 1 \geq 1.6 \mathrm{~L}:$} & \multirow{3}{*}{0.117} \\
\hline Yes & 4 & 13.3 & 9 & 30.0 & \\
\hline No & 26 & 86.7 & 21 & 70.0 & \\
\hline
\end{tabular}

MBC: Maximum breathing capacity. -FEV1: Forced expiratory volume in the first second.

Table (6): Distribution of study and control groups in relation to bedside pulmonary function tests after three days of the study, (total patients' number $=60$ ): -

\begin{tabular}{|c|c|c|c|c|c|}
\hline \multirow{2}{*}{ Bedside pulmonary function tests } & \multicolumn{2}{|r|}{ Study $(n=30)$} & \multicolumn{2}{|c|}{ Control $(n=30)$} & \multirow{2}{*}{ P-value } \\
\hline & & no. & no. & $\%$ & \\
\hline \multicolumn{6}{|l|}{ Before exercise: } \\
\hline \multicolumn{5}{|l|}{ Cardiopulmonary Reserve (CPR): } & \multirow{4}{*}{$0.006^{*}$} \\
\hline Limited CPR & 19 & 63.3 & 19 & 63.3 & \\
\hline Very poor CPR & 4 & 13.3 & 11 & 36.7 & \\
\hline Normal & 7 & 23.3 & 0 & 0.0 & \\
\hline Volume capacity (VC): & \multicolumn{2}{|c|}{$2533.33 \pm 472.22$} & 2166.6 & \pm 401.15 & $\frac{1}{0.002 *}$ \\
\hline \multicolumn{5}{|l|}{$\mathrm{MBC} \geq 60 \mathrm{~L} / \mathrm{min} \& \mathrm{FEV} 1 \geq 1.6 \mathrm{~L}:$} & \multirow[b]{2}{*}{0.052} \\
\hline Yes & 1 & 3.3 & 7 & 23.3 & \\
\hline
\end{tabular}




\begin{tabular}{|c|c|c|c|c|c|}
\hline \multirow{2}{*}{ Bedside pulmonary function tests } & & \multicolumn{3}{|c|}{ Study $(n=30) \quad$ Control $(n=30)$} & \multirow{3}{*}{ P-value } \\
\hline & & no. & & $\%$ & \\
\hline No & 29 & 96.7 & 23 & 76.7 & \\
\hline \multicolumn{6}{|l|}{ After exercise: } \\
\hline \multicolumn{5}{|l|}{ Cardiopulmonary Reserve (CPR): } & \multirow{4}{*}{$0.000 *$} \\
\hline Limited CPR & 8 & 26.7 & 22 & 73.3 & \\
\hline Very poor CPR & 0 & 0.0 & 6 & 20.0 & \\
\hline Normal & 22 & 73.3 & 2 & 6.7 & \\
\hline Volume capacity (VC) & \multicolumn{2}{|c|}{$2933.33 \pm 388.04$} & \multicolumn{2}{|c|}{$2316.67 \pm 404.36$} & \\
\hline \multicolumn{5}{|l|}{$\mathrm{MBC} \geq 60 \mathrm{~L} / \mathrm{min} \&$ FEV1 $\geq 1.6 \mathrm{~L}:$} & \multirow{3}{*}{0.052} \\
\hline Yes & 1 & 3.3 & 7 & 23.3 & \\
\hline No & 29 & 96.7 & 23 & 76.7 & \\
\hline
\end{tabular}

Table (7): Distribution of study and control groups in relation to bedside pulmonary function tests in the last day of the study, (total patients' number $=60$ ).

\begin{tabular}{|c|c|c|c|c|c|}
\hline \multirow{2}{*}{ Bedside pulmonary function tests } & \multicolumn{2}{|c|}{ Study $(n=30)$} & \multicolumn{2}{|c|}{ Control $(n=30)$} & \multirow{2}{*}{ P-value } \\
\hline & no. & $\%$ & no. & $\%$ & \\
\hline \multicolumn{6}{|l|}{ Before exercise: } \\
\hline \multicolumn{5}{|l|}{ Cardiopulmonary Reserve (CPR): } & \multirow{4}{*}{$0.000^{*}$} \\
\hline Limited CPR & 7 & 23.3 & 18 & 60.0 & \\
\hline Very poor CPR & 0 & 0.0 & 5 & 16.7 & \\
\hline Normal & 23 & 76.7 & 7 & 23.3 & \\
\hline Volume capacity (VC) & \multicolumn{2}{|c|}{$2950.00 \pm 401.51$} & \multicolumn{2}{|c|}{$2500.00 \pm 473.43$} & $0.000 *$ \\
\hline \multicolumn{5}{|l|}{$\mathrm{MBC} \geq 60 \mathrm{~L} / \mathrm{min} \& \mathrm{FEV} 1 \geq 1.6 \mathrm{~L}:$} & \multirow{3}{*}{0.237} \\
\hline Yes & 0 & 0.0 & 3 & 10.0 & \\
\hline No & 30 & 100.0 & 27 & 90.0 & \\
\hline \multicolumn{6}{|l|}{ After exercise: } \\
\hline \multicolumn{5}{|l|}{ Cardiopulmonary Reserve (CPR): } & \multirow{4}{*}{$0.000 *$} \\
\hline Limited CPR & 0 & 0.0 & 18 & 60.0 & \\
\hline Very poor CPR & 0 & 0.0 & 3 & 10.0 & \\
\hline Normal & 30 & 100.0 & 9 & 30.0 & \\
\hline Volume capacity (VC) & \multicolumn{2}{|c|}{$3366.67 \pm 260.42$} & \multicolumn{2}{|c|}{$2683.33 \pm 516.68$} & $0.000^{*}$ \\
\hline \multicolumn{5}{|l|}{$\mathrm{MBC} \geq 60 \mathrm{~L} / \mathrm{min} \& \mathrm{FEV} 1 \geq 1.6 \mathrm{~L}:$} & \multirow{3}{*}{0.237} \\
\hline Yes & 0 & 0.0 & 3 & 10.0 & \\
\hline No & 30 & 100.0 & 27 & 90.0 & \\
\hline
\end{tabular}

-MBC: Maximum breathing capacity.

-FEV1: Forced expiratory volume in the first second.

Table (1): Illustrates personal characteristics of study and control groups. Regarding to sex, it was noticed that more than one half on both groups were female . As regard to age, it was noticed that the main age in study and control groups are nearly similar (41.87 \pm $11.05 \& 42.80 \pm 11.54)$ respectively. No significant statistical difference was put into evidence between the two studied groups in relation to sex and age.

Table (2) shows clinical data of study and control groups. As regard to present illness, results revealed that there was no a statistical significant difference between study and control groups (P-value > 0.05). As regard to ICU stay, it was observed that there was no a statistical significant difference between study and control groups $(\mathrm{P}=0.433)$.

Table (3): Shows Hemodynamic monitoring of study and control groups in the first day of the study, after three day of the study and in the last day of the study. It can be noted from this table that there was no statistically significant difference between the two groups regarding the majority items of hemodynamic monitoring except MAP and WBC in the first day of the study and except the respiratory rate, serum $\mathrm{K}$ and $\mathrm{FIO}_{2}$ after three days of the study and except heart rate, respiratory rate, $\mathrm{CVP}, \mathrm{WBC}$ and serum $\mathrm{Na}$ in the last day of the study as it was found that there was a 
statistical significant difference between study and control groups $(\mathrm{p}<0.05)$.

Table (4): Shows that there was highly statistical significant difference between study and control groups in relation to chest expansion after exercise after three days of the study and in before and after exercise in the last day of the study $(\mathrm{P}=0.000)$. Also, it was noticed that there was a statistical significant diferrence between study and control groups in relation to chest expansion after exercise in the first day of the study and before exercise after three days of the study ( $\mathrm{P}=0.09 \& \mathrm{P}=0.014)$ respectively.

Table (5): Illustrates that there was no statistical significant difference between study and control groups before and after exercise in the majority items of bedside pulmonary function tests (P-value $>0.05$ ) except cardiopulmonary reserve and volume capacity as results show that there was highly statistical significant difference between study and control groups after exercise regarding volume capacity and there was statistical significant difference between study and control groups after exercise regarding cardiopulmonary reserve $(\mathrm{P}=0.008)$.

Table (6): Shows that there were statistical significant differences between study and control groups regarding the majority items of bedside pulmonary function tests before and after exercise after three days of the study (P-value $>0.05$ ) except MBC \& FEV1 .

Table (7): Illustrates that there were highly statistical significant differences between study and control groups regarding the majority items of bedside pulmonary function tests before and after exercise in the day of the study (P-value > 0.05) except MBC \& FEV1.

\section{Discussion}

In the current study, it was observed that patients with pneumonia, acute kidney injury (AKI) and pulmonary embolism were the high risk group for pleural effusion, and it was observed that pnumonia as the most common cause contributing to pleural effusion in less than half of patients in study group and in one third of patients in control group. Similar to this observation, study done by (Rahul \& Nick, 2015) who reported that an exudate is most likely to be associated with pneumonia. Estimates suggest that more than half of patients with pneumonia will develop pleural fluid.

In the current study, AKI was a significant cause of pleural effusion as it was responsible for pleural effusion in one third of patients in study group and less than one third of patients in control group. This come in inferior of study done by (Clare et al., 2010) who documented that renal disease is less common cause of pleural effusion.
In the current study, it was noticed that there was no a statistical significant difference between study and control groups in the first day of the study regarding vital signs except MAP, this is related to that both groups received care which maintained patients in stabilized condition and there are other multifactor affect vital signs rather than pleural effusion.

In the current study, it was noticed that there was a statistical significant difference between study and control groups after three days of the study and the last day of the study regarding respiratory rate, this is related to that patients received chest physiotherapy have improvement in pulmonary functions which reflected on respiratory rate as patients in study group after three days of the study and in the last day of the study has normal respiratory rate, inferior of this was happened on control group.

The results obtained in this study indicated that, there was significant increase in chest expansion and pulmonary function in study group than control group. It means that the standardized nursing care with using chest physiotherapy was more effective than the routine hospital care.

\section{Chest Expansion}

There was significant improvement of chest expansion in study group than control group after exercise as results showed that there was a statistical significant difference between study and control groups in the first day of the study and there were highly statistical significant difference between study and control groups regarding chest expansion after exercise after three days of the study and in the last day of the study. This in line with study done with Komal and Subin etal (2016) concluded that patients with pleural effusion who had undergone chest mobility exercises with incentive spirometer had shown statistically significant increase in chest expansion.

The physiological mechanism underlying the more increase in chest expansion in study group is probably due to that this group received chest physiotherapy included segmental breathing, stacked breathing exercise and chest mobility exercises which are supposed to act on the stretch reflex mechanism. Quick stretch on the external intercostal leads to facilitation of their contraction that assists in inspiration which leads to chest expansion and further lung expansion was increased. It helped in increasing inspiratory capacity and during expiration, it helped in full expiration there by helping the patient to relax comfortably.

Sarkar \& Sharma (July 2010) conducted study on segmental breathing exercises in 40 empyema patients and they found that chest expansion was increased at all the levels which in line with the results of the current study. 


\section{Bedside pulmonary function tests}

There was significant improvement of pulmonary function in study group than control group after exercise as results showed that there was highly statistical significant difference between study and control groups in the first day of the study, after three days of the study and in the last day of the study regarding Cardiopulmonary Reserve (CPR) and Volume capacity (VC) .

\section{Volume Capacity (VC)}

Pleural effusion is restrictive respiratory disease characterized by inspiration difficulty which may be because of abnormality in lungs or pleural cavity or patient may not be able to take inspiration due to collapse or restricted lung expansion. So in this condition there are reduced volume capacity Gunjal et al., (2015).

In study group there is significant increase in volume capacity due to the lungs are expanded considerably and the walls of alveoli are stretched maximum. Physiological mechanism underlying in more increase of volume capacity in study group is probably due to deep inspiration with facilitation of intercostal muscle contraction by passive intercostal stretch prior to inspiration.

Vikram and Kamaria (June 2012) conducted study on effect of intercostal stretch on pulmonary function parameters and they stated that the use of manual stretching procedures has become more established in cardiorespiratory physiotherapy to improve pulmonary functions. The results of the study showed, FEV1 and FVC in the study group significantly improved than the control group, which means intercostal stretch increased lung volume and lead lung function improvement. This come in line with the results of the current study which showed that there was a statistical significant difference between both groups after three days of the study and in the last day of the study regarding CPR which reflects that there are better improvement in pulmonary function in study group than control group.

Also, there are study done by Gunjal et al., (2015) who concluded that two weeks of segmental breathing exercises have better effect on chest expansion and pulmonary function, and this in line with the results of the current study which showed the same results.

\section{Conclusions}

Based on the results of this study, it could be concluded that: implementing standardized nursing care by using chest physiotherapy including (chest mobility exercises, segmental breathing, stacked breathing, deep breathing exercise with using incentive spirometer) had significant improvement on chest expansion and pulmonary functions than the routine hospital care.

\section{Recommendations}

The study recommended that

- Emphasize the importance of applying chest physiotherapy protocol in patients with the pleural effusion and its importance in improving chest expansion and pulmonary functions .

- Emphasize the importance of accurate monitoring of pulmonary function in detection and preventing any problem or deterioration in patient with pleural effusion.

- The nurse should assess chest condition daily to follow the trend of pulmonary functions and to determine whether it is stable, getting better or getting worse and comparing it with the base line of the patient and escalating the case to the medical staff if there are any complain from the patient.

- Reapply this research on a larger probability sample acquired from different geographical areas in Egypt for generalization

\section{References}

1. AARC Clinical Practice Guideline, (1991): Reprinted from the December 1991 issue of Respiratory Care [Respir Care 1991; 36(12):1402-1405].

2. Agarwal K., \&| Solomen S., (2016): Comparative study between chest mobility exercises with incentive spirometry versus chest mobility exercises with stacked breathing on chest expansion in subjects with unilateral pleural effusion in International Journal of Development Research, Vol. 06, Issue, 06, 8034-8038.

3. Agostini P., \& Singh S., (2009): Incentive spirometry following thoracic surgery: what should we be doing? Jun; 95(2):76-82. Epub 2009 Mar 3.

4. Bhatnagar R., \& Maskell N., (2015): The modern diagnosis and management of pleural effusions in BMJ 2015;351:h4520 doi: 10.1136/bmj.h4520.

5. Gunjal S., Shinde N., Kazi A., (2015): Effectiveness of deep breathing versus segmental breathing exercises on chest expansion in pleural effusion. Int $\mathbf{J}$ Health Sci Res. 2015; 5(7):234-240.

6. Hooper C., Lee G., Maskell N., (2010): Investigation of a unilateral pleural effusion in adults: British Thoracic Society pleural 
disease guideline 2010. Thorax; 65 (Supp12) :ii4eii17. doi: 10.1136 /thx. 2010.136978.

7. Hsieh Y., Daniel A., Michael D., (1998): A simple method of sample size calculation for linear and logestic regression .statistics in medicine, Volume 17, Issue 14.

8. Incekara F., Tikici D., Nomenoglu H., (2018): Pleural Effusions. Insights Chest Dis Vol.3 No.1:1.

9. José C., Yataco \& Raed A., Dweik, (2014): Pleural effusions: Evaluation and management in cleveland clinic journal of medicine, vol. 72, No.10 .

10. Kakizaki F., Shibuya M., Yamazaki T., Yamada M., Suzuki H., \& Homma I., (1999): Preliminary report on the effects of respiratory muscle stretch gymnastics on chest wall mobility in patients with COPD. Respir Care, 44:409-14.

11. Kisner C., Colby L., (2007): Therapeutic Exercise Foundations and Techniques.5th edition, jaypee, Philadelphia (PA): F.A. Davis Company; 2007: 862-862.

12. Kollef (2012): the Washington Manual of Critical Care. United States of America, Lippincott Williams and Wilkins Publications.

13. Light R., (1997): Diagnostc principles in pleural disease. Eur Respir J 10: 476-481.

14. Milojević M, Kuruc V(2003):Laser biostimulation in the treatment of plerisy . 2003 Nov-Dec;56(11-12):516-20.

15. Murphy F., \& pyrne G., (2010): The role of the nurse in the management of acute kidney injury. British journal of nursing, 2010; 19(3), pp. (146-152).

16. Polastri M., Pantaleo A., (2012): Managing a left pleural effusion after aortic surgery; European Review for Medical and Pharmacological Sciences. 2012;16(4 Suppl):78-80.

17. Providence Care (2008): available from URL

http://www.providencecare.ca/obkects/conte nt_revision/download.cfm/revision_id-

4/Breath $\% 20$

Stacking\%20handbook.pdf/2008;1-11.

18. Sarkar A., Sharma A, Razdan S, Kuhar, Bansal N., Kaur G., (2010): Effect of segmental breathing exercises on chest expansion in empyema patients; Indian Journal of Physiotherapy and Occupational Therapy, July 2010; volume 3(4) ;17-20.

19. Vikram M., Leonard J., \& Kamaria K., (2012): Chest Wall Stretching Exercise as an
Adjunct Modality in Post Operative Pulmonary Management. Mar 4. 